\title{
Challenges and Enablers for Rapid Product Development
}

\author{
Jordan Verrollot, University of Oulu, Oulu, Finland \\ Arto Tolonen, University of Oulu, Oulu, Finland \\ Janne Harkonen, University of Oulu, Oulu, Finland \\ Harri J. O. Haapasalo, University of Oulu, Oulu, Finland
}

\begin{abstract}
This article describes how new product development (NPD) is critical to maintaining a strong market position. However, full-scale NPD may consume too much time and resources when necessary to react quickly to customer needs or emerging business opportunities. Rapid development (RaDe) is a type of incremental product development complementing the organizations' existing NPD process. In RaDe, new sales items are created by redesigning or upgrading existing products inexpensively, and in a timely manner. This article aims at clarifying the challenges and enablers relating to RaDe implementation in four case companies and by the means of reviewing literature. The identified challenges include the difficulty of differentiating between product developments models, the lack of clear definition for RaDe and issues in product data management. The enablers include structuring and managing projects differently compared to NPD, the utilization of existing supply-chain capabilities and the designed products fitting the current business processes to enable rapid product ramp-ups.
\end{abstract}

\section{KEYWORDS}

Challenges, Enablers, New Product Development Process, NPD, RaDe, Rapid Development, Rapid Product Development

\section{INTRODUCTION}

The development and launch of successful new products are increasingly critical to allow market leadership, healthy market share, and sustained growth (Barczak \& Kahn, 2012; Unger \& Eppinger, 2009; Wheelwright \& Clark, 1992). New products are created using New Product Development (NPD) processes, which have been designed to be repeatable in order to reduce risks, cost and nonquality (Cooper, 1986; Ulrich \& Eppinger, 2000). However, milestone-driven NPD projects have been criticised to be too linear, too rigid and too planned for small and dynamic projects (Cooper, 2014) that require reacting quickly to sudden product development needs. Phases and milestones may also stop the project for unnecessary long times (Ottosson, 2004) hindering the possibilities of conducting the development rapidly. One single development concept is not enough to fit all the various ranges of development needed in terms of cost, time or risk (Becker, 2006; Cooper, 2008; Ward, 2007).

Organisations that are slow in developing new products and are unable to meet sudden demands in a timely fashion often lose against those with a more agile development process (Cohen et al., 1996; Smith, 1990). Therefore, shorter lead times and customer responsiveness are seen as key elements that influence the firm's success and performance (Jayachandran et al., 2004; Krasnikov 
\& Jayachandran, 2008; Sousa et al., 2010). Companies are facing pressures to supply new products constantly and rapidly to the market while the ability to react to specific customer needs through the product range is seen vital to succeed in global competition (Forza \& Salvador 2008). Due to the growing importance of innovation and product development in establishing and maintaining a strong position in the increasingly competitive business area (Moreno-Moya \& Munuera-Aleman, 2016; Smith \& Reinertsen, 1998), the demands on product development performance, in terms of speed and efficiency have become more stringent (Cedergren et al, 2010; Van Echtelt et al., 2008; Yadav \& Singh, 2008). Therefore, the importance of the companies' capabilities to evaluate their product development performance has increased (Johnson \& Kirchain, 2011).

Many techniques and approaches have been studied in the literature to reduce lead-time of product development (Langerak \& Hultink, 2008). Companies increasingly utilize shortened NPD models to reduce the development lead-times of small projects; 75 percent of top performing businesses use some form of scalability in their product development processes. (Cooper \& Edgett, 2012). Cooper (2008) has proposed to scale down his famous milestone driven product development model in order to suit different project needs. The lightest version is meant to address very small projects requiring minor changes to existing products such as simple customer requests (Cooper, 2014). Despite the extensive research on the methods to improve the process of developing new products, limited attention has been paid to small and fast product development projects, especially in the business-to-business environment (Cooper et al., 2004; Kaikkonen et al. 2016). The previous studies on the topics (e.g. Cooper, 2008; Hänninen et al., 2014; Kaikkonen et al., 2017; Niskanen et al., 2015; Vigna et al., 2015) do not comprehensively examine the challenges and enablers related to implementing and running those kinds of product development projects.

The motivation for the study arises from the growing significance of small-scale and rapid incremental product development to fulfill the unexpected market and customer needs (Cooper, 2008; Kaikkonen et al., 2017). In this study, the rapid product development (RaDe) projects are defined as fast product development activities, noticeably smaller in scope and size than projects requiring multiple stages and gates. Based on minor modifications of existing products, new sellable items are created to complement the company's product portfolio. Although organizations may not have defined and organized $\mathrm{RaDe}$, product development needs that require quick product creation do emerge suddenly. Therefore, this paper aims at examining and clarifying the related challenges and enablers. The study is realized as a combination of reviewing the literature and analyzing the practices of companies operating in Finland and Sweden.

The paper is organized as follows. The following section focuses on identifying how the literature conveys the small-scale product development model. The research process and method and the results section follow. The results explain the challenges related to RaDe and the enablers for its implementation. Finally, the last section presents the discussion and conclusions.

\section{LITERATURE REVIEW}

Product development process is connected to the product portfolio management as it strategically and cost-efficiently determines the best set of products to create, sell, deliver and care (Georgiopoulos et al. 2002; Sadeghi \& Zandieh, 2011). Correspondingly, product portfolio management affects the product development process and the supply chain processes by selecting the product to be created and delivered. Consequently, the introduction by the product development process of new products without removing existing ones from the product portfolio will generate an explosion of the portfolio (Tolonen et al., 2015). The product proliferation and cannibalization will lead to increased numbers of sales items, purchased components, suppliers as well as higher inventory levels and longer lead times (Abbey et al., 2013; Fisher et al., 1999).

Product development aims at moving new products, that meet the customer's needs and the strategic goal of the company, from idea generation into a market introduction, including product 
design, market study, and marketing analyses (Browning \& Ramasesh, 2007; Cooper, 2005; Ulrich \& Eppinger, 2008). It comprises sequential steps or set of activities beginning with the perception of a market opportunity and ending in the production, sale, and delivery of a product (Ulrich \& Eppinger, 2008). Since the 90s, a number of NPD frameworks (e.g., Cooper, 2001; Ulrich \& Eppinger, 2008; Wheelwright \& Clark, 1992) have emerged to meet the various needs of organizations. As the complexity of different product development projects differs, the scope, decision-making process, number of activities, risk level, amount of resources, and funding committed also vary greatly (Cooper, 2008). Utilising an identical process for all the product development projects may result in rushing rapid projects ahead longer ones and generating unnecessary delays (Ward, 2007). In an environment with sudden and dramatic changes, product development delay may inhibit success while rapid and efficient commercialization of new products has become a top priority in many organizations (Harmancioglu et al., 2007). In the last two decades, the relative portion of incremental NPD has greatly increased in enterprises compared to radical innovations through full-scale product development (Cooper, 2013). One of the main objectives of incremental product development is to make the offering more attractive and valuable to the customer, therefore leading to increased sales and higher profit (Gautam \& Singh, 2008). Firms with a fast and productive new product development process are seen to shape partly the financial success of the product (i.e., revenue and profitability) (Brown \& Eisenhardt, 1995). Cooper (2008) has proposed the next Generation Stage-Gate ${ }^{\circledR}$ including a shorter and lighter version of the famous milestone-driven product development model. In order to suit different project needs (such as minor changes projects), phases are combined and the number of gates is reduced. Lately, different studies have been carried out to cover this type of small-scale product development that requires a minimal engineering effort, a short development and delivery time (e.g. Hänninen et al., 2014; Kaikkonen et al., 2017; Niskanen et al., 2015; Vigna et al., 2015). Those studies address issues of decision-making (Hänninen et al., 2014), team organization (Kaikkonen et al., 2017; Vigna et al., 2015) or supplier involvement (Niskanen et al., 2015) regarding rapid product development projects.

Firms face similar challenges of bringing new products to market faster in an increasingly competitive environment (such as the inability to predict the development duration or managing changing requirements) (Ledwith et al., 2006). The implementation of the full-scale NPD process - even in a lighter way - does not seem to be the appropriate method in case of rapid development needs and thus poses challenges for companies. Companies should be able to balance the short-term need for incremental development with the long-term requirements for radical innovation (Birkinshaw \& Gibson, 2004). This situation generates challenges for companies in that it necessitates different and often contradictory structures, processes and cultures within the same organization (Tushman \& O'Reilly, 1996). More practically, Hänninen et al. (2013) uncovered the challenges related to the need to respond quickly to customer preferences in case of rapid productisation (e.g., how to understand, identify and document the customer preferences right from the beginning, how to ensure a rapid turnaround time for the specification and development plan). Rapid development and productization can also be supported by understanding the productization concept and its relation to product portfolio (Harkonen et al., 2015; 2017). In faster product development, problems also occur in term of supplier involvement. Compared to traditional NPD and due to time constraint, the cost tends to rise, the probability of defects increases and late deliveries may happen due to poor delivery capability or communication (Niskanen et al., 2015).

Lean product development has been one of the leading approach adopted by organizations to improve their NPD process and particularly to shorten lead times. For instance, product platform strategy, overlapping in development stages, good cross-functional involvement and communications, as well as supplier capabilities are seen to decrease NPD time (Kärkkäinen et al., 2001; León \& Farris, 2011; Robertson \& Ulrich, 1998). Other techniques to accelerate NPD have been investigated and five approaches are seen to increase the development speed: supplier involvement, lead user involvement, speeding up activities and tasks, training and rewarding of employees, and simplification of organizational structure (Langerak \& Hultink, 2008). However, the focus is more on the full-scale 
NPD and techniques to reduce its lead-time, whereas specifically addressing the managerial point of view and enablers for small-scale and rapid product development projects are limited. Furthermore, techniques recognized for NPD may increase the development time in case of fast product development projects, such as the supplier involvement that can cause late deliveries (Niskanen et al., 2015). Smith (1990) provided elements for a successful rapid product development, including a product structured for rapid development, a co-located and dedicated team designed for rapid decision making, streamlined management techniques or sensitivity to time's value. A good balance of the different competencies available is also seen to enhance the rapid product development capabilities (Hänninen et al., 2014). Implementing rapid product development with a similar focus as long-term product development is recognized to be more valuable for NPD organizations because the tasks, resource utilization, and prioritization can be done more effectively and improve the company's profitability (Kaikkonen et al., 2017).

Others aspects have been identified to support the success of rapid product development projects. Effective governance contributes to the product development success and includes aspects such as the right people involved in decision-making, the appropriate mechanisms for feedback and accountability as well as a suitable process to make decisions (Oakes \& von Weissenberg, 2015). The necessity of faster product development demands more flexible organizations and effective implementation of cross-functional teams has become critical to the success of product development projects (Griffin, 1997; Holland et al., 2000). However, the incremental NPD projects may not require the same level of cross-functional integration than larger and very complex projects (Jugend et al., 2017). Bringing together teams of experts to conduct product development activities is valuable to accelerate the projects and gather all the required knowledge (Brettel et al., 2011). The NPD teams can be functional, lightweight, heavyweight and self-managing (autonomous) (Wheelwright \& Clark, 1992). Selected characteristics of self-managing teams have been recognized to achieve improvements in rapid, incremental development projects (Kaikkonen et al., 2017). Additionally, effective interaction between the different stakeholders is a particularly important success factor of product development success (Ernst, 2002; Knudsen, 2007).

Business case analysis is an important task in product development to decide whether a project is worth investing and will be accepted (Cooper, 2011; Otto \& Wood, 2001). The complete business case analysis conducted in major NPD may be too laborious and time-consuming in smaller and faster projects. Nevertheless, the equilibrium between the time constraint of light product development projects and the effort into business case calculation is crucial to make reasoned decisions (Kinnunen et al., 2014). As part of product development organization, the targets for the lighter product development projects should be aligned with the product portfolio management targets, which are connected with the company's strategy (Cooper, 1999; Tolonen et al., 2014). To control the achievement of the targets, companies utilize key performance indicators (KPIs) which should be related to their respective goals (Dombrowski et al., 2013; Maté et al., 2017).

Responding to the customer demand quickly requires the capability to manage the product data effectively and product data management (PDM) is a crucial component to support this objective (Hooi Leng, 2002; Yang et al., 2007). PDM systems facilitate sharing the right product information at the right time resulting in reduced product development lead-time and cost (Nair et al., 2001; Philpotts, 1996). Product modularity is also an important method used by many firms to shorten NPD lead-time, minimise product development cost and create successive variants of the same product line (Mikkola \& Gassmann, 2003; Danese \& Filippini, 2010). For rapid product development, the time pressure prevents the changes of in the supply chain process and entails an anticipation of the supply chain constraints at an early stage (Lee \& Sasser, 1995; Pero et al. 2010). Design for X (DfX) addresses possible product design issues into the product development phase so that the new product will conform to the existing business processes (Holt \& Barnes 2010; Lehto et al., 2011). Successful DfX implementation can lead to benefits, which include decreased product lifecycle cost, efficient product design, quality improvement and shortened time-to-market (Barbosa \& Carvalho, 2013; Gatenby \& Foo, 1990; Kuo et al., 2001). 
Figure 1. Research process

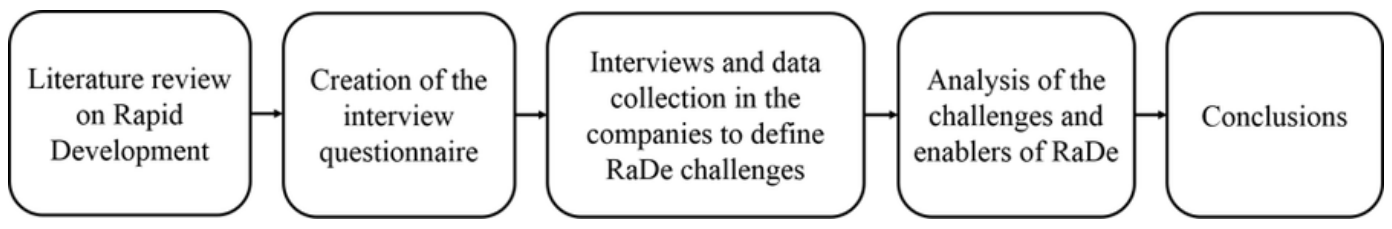

\section{RESEARCH PROCESS AND METHOD}

As there has been limited research on the topic of rapid development, the present study is exploratory in nature and applies an inductive approach (cf. Thomas, 2006). The research process is presented in Figure 1.

This study utilizes qualitative and inductive research methods. The existing literature was reviewed to obtain an understanding of the research that has been carried out on RaDe. The literature review provided a basis for the empirical analysis, which was performed through a multiple-case study. Four companies operating in Finland and Sweden were selected as a data source (one case company has been analysed at two different sites possessing two different organisations, resulting in two different cases) and serve as a basis for empirical studies on different business areas (e.g. hardware, software and service) and different types of industry. The main company selection criteria were to operate in a business-to-business environment, to conduct NPD projects actively and to wish to develop their way of organizing fast responses to development needs.

This study was part of a research project related to rapid product development, which took place between September 2015 and September 2017. The qualitative research data were collected by creating and implementing a semi-structured interview frame and by analyzing the companies' documentation (e.g., product development process descriptions). The interviews were conducted with twenty specialists, selected based on their professional background and expertise (cf. Eisenhardt, 1989). At each company, interviews were conducted with all the informants at the same time allowing "multiple respondents to provide relevant input across functions and hierarchy within each organisation [to] yield a more comprehensive view of new product development management practices" (Barczak et al., 2006: p. 518) and help to identify common problems that may affect the interviewee's responses (Yin, 2003). The selected case companies' information and interviewee characteristics are presented in Table 1.

Eight semi-structured interviews, with 20 informants, were conducted by seven researchers; the interview questionnaire was sent in advance so that the informants had the opportunity to get accustomed to the questions beforehand. During each interview and alternatively, one researcher asked the questions by referring to the interview guide while the others listened, took notes and provided support in following the interview structure. The written notes were presented directly on a screen to get immediate validation from the informants. All the interviews were recorded, transcribed and completed by adding notes. After collecting all the data, analyses were conducted within every case to obtain a comprehensive understanding of the RaDe challenges of each individual case. Additionally, a cross-case analysis was performed to compare the different cases with one another. The results were discussed and confirmed during four separate focus group meetings with representatives of all the analyzed companies. All the involved researchers took part of the proof of result to avoid misinterpretations.

The questionnaire and the data analysis were divided into four main subsets: product development project portfolio management, the process adopted for rapid development and project management, team setup and collaboration, and Design for X (DfX) (Appendix). As DfX is irregularly understood in the case companies, it has been presented as the product design requirements and guidelines from the receiving business processes point of view in order to avoid product specific investments and processes. The concept is presented in the same way in this paper. 


\section{RESULTS}

\section{Rapid Development Challenges}

The case companies are utilizing two to five different models to develop new products or technologies. Those models represent different needs for the companies, from long and expensive technology/major new product development to development involving faster and cheaper minor changes. Lately, every case company has seen an increased number of activities for nearly all the product development models.

The current operational model of the RaDe type activity is based on engineering change management (ECM) in every company. Initially, ECM aims at improving or reducing the cost of existing products without creating new sales items. However, the intention of RaDe is the development of the new sales items. The timeframe, goals, and organization to run RaDe projects vary in the different companies. The company B uses ECM to create new sales items based on existing materials, production parameters and manufacturing technologies while the others utilize ECM for technical modifications of existing sales items without creating a new product. Unlike the others, the case company D does not possess a permanent RaDe line organization. All the companies utilize their existing manufacturing technologies and delivery models; no new capabilities in the supply chain are created during RaDe projects.

Product portfolio management is applied to every company but the practices differ. All the case companies utilize business cases for evaluating and prioritizing projects. Project portfolio management of RaDe is assigned to a specific steering team (ST) in all companies but the line organization of the ST Chairman may be different and the frequency of the meetings differs. The criteria for selecting RaDe development model are almost similar such as timeframe, cost, and workforce. All the case companies have modular product structures available. As a major difference to others, the company A is the only one to fully use and recognize the product lifecycle phases.

Table 2 shows an overview of the companies' product development including their current way of developing products rapidly.

Table 1. Case companies' information and interviews characteristics

\begin{tabular}{|c|c|c|c|c|c|}
\hline Case & $\begin{array}{c}\text { Company type and } \\
\text { size }\end{array}$ & $\begin{array}{l}\text { Product } \\
\text { type }\end{array}$ & $\begin{array}{c}\text { No of } \\
\text { interviews }\end{array}$ & $\begin{array}{c}\text { No of } \\
\text { informants }\end{array}$ & Role of the informants \\
\hline A & $\begin{array}{l}\text { Telecommunication } \\
\text { and communication } \\
\text { equipment. } \\
\text { Large }\end{array}$ & $\begin{array}{l}\text { Tangible } \\
\text { and } \\
\text { intangible }\end{array}$ & $\begin{array}{l}2(1,5 \text { full } \\
\text { days })\end{array}$ & 4 & $\begin{array}{c}\text { - Head of Product Development } \\
\text { - Head of Product Engineering } \\
\text { • Product Manager } \\
\text { - Technical Product Manager }\end{array}$ \\
\hline \multirow[t]{2}{*}{ B } & \multirow{2}{*}{$\begin{array}{l}\text { Iron and steel } \\
\text { Large }\end{array}$} & \multirow{2}{*}{ Tangible } & \multirow{2}{*}{$\begin{array}{c}2 \text { different } \\
\text { sites (1 } \\
\text { full day } \\
\text { interview } \\
\text { per site) }\end{array}$} & 4 & $\begin{array}{c}\text { - Head of Product Development } \\
\text { - Product Development Manager } \\
\text { - Product Managers }\end{array}$ \\
\hline & & & & 2 & $\begin{array}{c}\text { - Product Development Manager } \\
\text { • Quality Manager }\end{array}$ \\
\hline $\mathrm{C}$ & $\begin{array}{l}\text { Electromagnetic } \\
\text { radiation equipment. } \\
\text { Large }\end{array}$ & Tangible & $\begin{array}{l}2(1,5 \text { full } \\
\text { days })\end{array}$ & 4 & $\begin{array}{l}\text { - Chief Technical Officer } \\
\text { - Project Management Director } \\
\text { - Product Data Manager } \\
\text { - Product Manager }\end{array}$ \\
\hline $\mathrm{D}$ & $\begin{array}{c}\text { Construction } \\
\text { installation equipment. } \\
\text { Medium }\end{array}$ & $\begin{array}{l}\text { Tangible } \\
\text { and } \\
\text { intangible }\end{array}$ & $\begin{array}{l}2(1,5 \text { full } \\
\text { days })\end{array}$ & 6 & $\begin{array}{l}\text { - CEO and Vice CEO } \\
\text { - Head of R\&D } \\
\text { - R\&D Project Manager } \\
\text { - Program Manager } \\
\text { - Product Manager } \\
\text { - Quality Consultant }\end{array}$ \\
\hline
\end{tabular}


For this study, the ECM model is considered as the companies' RaDe model because it is the fastest product development model involving technical modifications of an existing product or new sales items creation. Later on, RaDe will be the only term used to describe this kind of model.

\section{Rapid Development Challenges}

All interviewed companies see a potential for improvement in their rapid product development models. Practical challenges for RaDe emerged from the data analysis and the discussions with the case companies' representatives. The results are presented following the interview findings and divided into the six groups:

1. Challenges in general

2. Challenges on governance models and team setups

3. Challenges on RaDe processes and tools

4. Challenges on RaDe targets and key performance indicators (KPIs)

5. Challenges in product data management (PDM)

6. Challenges on DfX

\section{Challenges in General}

Rapid development is seen as a generic challenge in the case companies' regardless the maturity, the history and the industry sector of the company. Due to the increased level of competition, the development of new products is seen crucial for the case companies and has recently caused an increasing number of activities in product development. As the full scale, expensive and resource

Table 2. Case companies' product development models and RaDe

\begin{tabular}{|c|c|c|}
\hline Case & $\begin{array}{c}\text { Different product } \\
\text { development models }\end{array}$ & Current Rapid development model \\
\hline A & $\begin{array}{l}5 \text { models } \\
\text { (technology, product } \\
\text { platform, major new product, } \\
\text { medium enhancement, minor } \\
\text { changes) }\end{array}$ & $\begin{array}{l}\text { - ECM workflow, technical modifications of existing sales items } \\
\text { - Permanent "RaDe" line organization, co-located team } \\
\text { - Timeframe: } 1-2 \text { months, up to } 6 \text { months } \\
\text { - } 200 \text { projects per year } \\
\text { - RaDe project portfolio management: bi-weekly meeting } \\
\text { - Goal: cost reductions, quality improvements }\end{array}$ \\
\hline B1 & $\begin{array}{l}2 \text { models } \\
\text { (major new product, minor } \\
\text { changes) }\end{array}$ & $\begin{array}{l}\text { - ECM workflow creating new sales items } \\
\text { - Permanent "RaDe" line organization, co-located team } \\
\text { - Timeframe: } 1-2 \text { days } \\
\text { - Hundreds of projects per year } \\
\text { - RaDe project portfolio management: weekly meeting } \\
\text { - Goal: new product functionalities, cost reduction, competition }\end{array}$ \\
\hline B2 & $\begin{array}{l}2 \text { models } \\
\text { (major new product, minor } \\
\text { changes) }\end{array}$ & $\begin{array}{l}\text { - ECM workflow creating new sales items } \\
\text { - Permanent "RaDe" line organization, co-located team } \\
\text { - Timeframe: } 1-2 \text { days, up to one month } \\
\text { - Hundreds of projects per year } \\
\text { - RaDe project portfolio management: monthly meeting } \\
\text { - Goal: New customer needs with high-quality aspects }\end{array}$ \\
\hline $\mathrm{C}$ & $\begin{array}{l}3 \text { models } \\
\text { (major new product, medium } \\
\text { enhancement, minor } \\
\text { changes) }\end{array}$ & $\begin{array}{l}\text { - ECM workflow, technical modifications of existing sales items } \\
\text { - Permanent "RaDe" line organization, co-located team } \\
\text { - Timeframe: } 2-3 \text { months } \\
\text { - Tens of projects per year } \\
\text { - RaDe project portfolio management: bi-weekly meeting } \\
\text { - Goal: very fast time-to-market, desire for growth }\end{array}$ \\
\hline $\mathrm{D}$ & $\begin{array}{l}3 \text { models } \\
\text { (major new product, medium } \\
\text { enhancement, minor } \\
\text { changes) }\end{array}$ & $\begin{array}{l}\text { - ECM workflow, technical modifications of existing sales items } \\
\text { - Specialised individuals, co-located } \\
\text { - Timeframe: } 1-6 \text { months, up to } 9 \text { months } \\
\text { - } 50 \text { projects per year } \\
\text { - RaDe project portfolio management: weekly meeting } \\
\text { - Goal: creating sales revenue, cost reductions, quality improvements }\end{array}$ \\
\hline
\end{tabular}


consuming new product development does not fit every case, companies also strive to use a faster product development models in case of incremental product development needs with critical timeframes. The selection of the right product development model is seen as a common challenge in the case companies. Even though the companies have criteria to select the RaDe type of development, it appears to not always match the expected scope at the end of the project (e.g., too long or too costly project). Table 3 presents the companies' specific general challenges related to RaDe.

\section{Challenges on Governance Models and Team Setups}

Governance models for RaDe are not seen to be clear in every case company. The company A presents the most advanced and structured governance model. The responsibilities in design/product decisionmaking and project execution are clear. However, challenges occur regardless the characteristic of the governance of the case companies. Product ownership related to rapid development activities is sometimes seen uncertain. In the case company B1, it is not clear who owns the product and confusion may arise between technical portfolio and commercial portfolio ownership. Another common challenge is related to the decision-making to start RaDe projects. This is shown for example in the case company $\mathrm{D}$, in which some products have been developed through $\mathrm{RaDe}$ in order to support the sales of the core product but they have ended inactive in the portfolio and not sold as planned. RaDe team setups also differ between companies and even inside the same company. In the company B, site $\mathrm{B} 1$ possesses a fully committed line organization for RaDe while in site B2, RaDe activities are part of a quality team. Table 4 presents the companies' specific challenges related to RaDe governance models and team setups.

\section{Challenges on RaDe Processes and Tools}

$\mathrm{RaDe}$ has not been described as a clear process in any of the case companies. Mostly the RaDe activities are described as an ECM type of workflow, although RaDe process in case B2 is not represented nor described. Tools to run RaDe projects appear to be lacking and challenging. Some $\mathrm{RaDe}$ specific templates and tools have been developed in some case companies in order to manage RaDe activities (e.g., case D uses task card to document and follow the product modification) but tools for prioritization, evaluation, and decision-making are lacking. Table 5 presents the companies' specific challenges related to RaDe processes and tools.

Table 3. Specific general challenges related to RaDe

\begin{tabular}{|c|c|}
\hline Case & Specific general challenges related to $\mathrm{RaDe}$ \\
\hline A & $\begin{array}{l}\text { - Difficulties in deciding if a required modification should be implemented through Rapid development (i.e. } \\
\text { modifying an existing product) or as features to a new product. } \\
\text { - RaDe concept for new product creation is non-existing but well utilized in further improvement of existing } \\
\text { products. }\end{array}$ \\
\hline B1 & $\begin{array}{l}\text { - The product portfolio is growing and its clean-up is not adequately executed. } \\
\text { - The modification request is often unclear. }\end{array}$ \\
\hline $\mathrm{B} 2$ & $\begin{array}{l}\text { - RaDe process is not visually represented. } \\
\text { - The modification request is often unclear. }\end{array}$ \\
\hline $\mathrm{C}$ & $\begin{array}{l}\text { - The lack of human resources causes inefficiency to carry out RaDe projects. } \\
\text { - Medium enhancement product development model overlaps the RaDe model. } \\
\text { - RaDe concept for new product creation is non-existing. }\end{array}$ \\
\hline $\mathrm{D}$ & $\begin{array}{l}\text { - The product development team culture is not enough cross-functional yet. } \\
\text { - The current RaDe model timeframe differs greatly. } \\
\text { - RaDe concept for new product creation is non-existing. }\end{array}$ \\
\hline
\end{tabular}


Table 4. Specific challenges on governance models and team setups

\begin{tabular}{|c|c|}
\hline Case & Company-specific challenges on governance models and team setups \\
\hline A & $\begin{array}{l}\text { - Decision-making related to multiple products is a challenge (components are used in tens of different } \\
\text { products). } \\
\text { - The flow of information is challenging due to the size and the worldwide product development teams of the } \\
\text { company. }\end{array}$ \\
\hline B1 & - No specific challenges. \\
\hline B2 & $\begin{array}{l}\text { - No RaDe team in place. } \\
\text { - The governance model and organization of RaDe is not clear for a part of the portfolio. } \\
\text { - Clear responsibilities and structure are lacking. }\end{array}$ \\
\hline $\mathrm{C}$ & $\begin{array}{l}\text { - No fully dedicated team and no full commitment to the RaDe projects. } \\
\text { - Resources scarcity and attribution conflict. } \\
\text { - Lack of project management and clear responsibilities. }\end{array}$ \\
\hline $\mathrm{D}$ & $\begin{array}{l}\text { - No RaDe team in place. } \\
\text { - Decision-making in initiating RaDe projects is not formalized. } \\
\text { - Lack of visibility on the ongoing projects, their number and the status of the resource utilization. }\end{array}$ \\
\hline
\end{tabular}

\section{Challenges on RaDe Targets and Key Performance Indicators}

Case companies have clear targets and KPIs for RaDe initiative, including the traditional targets - cost, time and quality. In case companies focusing their RaDe activities on cost reduction and modifications of existing products (case companies A, C, D), the targets setting is mostly manufacturing, testing and quality related. In contrast, companies that aim for new sellable products (case company B) have a wider business related targets setting. The follow-up of the business case is a common challenge for the case companies. The developed product is not systematically evaluated to determine whether the expected targets defined in the business case have been reached or not. Table 6 presents the companies' specific challenges related to RaDe targets and KPIs.

\section{Challenges on Product Data Management}

PDM is seen as a common challenge for every case company. In the cases A, B1, and C, RaDe team is responsible for the data management activities related to the product changes. Regardless the data management responsibilities, getting detailed data for the product development may be complex due to fragmented databases and data sources. As an example in case company $\mathrm{D}$, a lot of product data, documentation, data sheets which are not centrally available makes it difficult to efficiently retrieve the needed information for dealing with RaDe projects. Table 7 presents the companies' specific challenges related to PDM in RaDe.

\section{Challenges on $D f X$}

DfX concept has been understood and implemented differently. It is known as a concept in only two case companies. In case company A, DfX has been developed for many years and the implementation of the process is systematic while in other case companies the concept is not even known as a topic. The lack of DfX guidelines and requirements management in case of RaDe cause challenges in the rapid delivery of the products. In company $\mathrm{D}$, product design changes may cause issues in product manufacturing, packaging, and installation, thus extending the shipment of the product to the customer. However, to allow fast and cost-efficient RaDe projects, the companies aim at no change in the receiving business processes due to product design. In company $\mathrm{C}$, it is specified that in the case of $\mathrm{RaDe}$, no new assembly, test and verification processes should be done as well as the field-proven building blocks and shelf components should be used in order to avoid lengthening the development time. Table 8 presents the companies' specific challenges related to DfX in RaDe. 
Table 5. Specific challenges on RaDe processes and tools

\begin{tabular}{|c|c|}
\hline Case & Company-specific challenges on RaDe processes and tools \\
\hline A & $\begin{array}{l}\text { - RaDe is not described as a process but as a lighter workflow type of activity and decision-making } \\
\text { description. } \\
\text { - Challenges in combining hardware and software, which are partly developed independently. }\end{array}$ \\
\hline B1 & $\begin{array}{l}\text { - No active product lifecycle management in use. } \\
\text { - No active management of product ramp downs. } \\
\text { - Unformulated development request acceptance causing inefficiency. } \\
\text { - Utilisation of old tools. }\end{array}$ \\
\hline B2 & $\begin{array}{l}\text { - No active product lifecycle management in use. } \\
\text { - No active management of product ramp down. } \\
\text { - RaDe process is not represented nor described. Creation of the RaDe workflow is seen as a challenge } \\
\text { (description, implementation, follow-up) } \\
\text { - Utilisation of old tools. }\end{array}$ \\
\hline $\mathrm{C}$ & $\begin{array}{l}\text { - RaDe projects do not employ an organized process and could be better structured. } \\
\text { - Product lifecycle management model is under development and yet to be in use. }\end{array}$ \\
\hline $\mathrm{D}$ & $\begin{array}{l}\text { - No active product lifecycle management in use. } \\
\text { - No defined process to communicate the design changes. }\end{array}$ \\
\hline
\end{tabular}

Table 6. Specific challenges on RaDe targets and KPIs

\begin{tabular}{|l|l|}
\hline \multicolumn{1}{|c|}{ Case } & \multicolumn{1}{c|}{ Company-specific challenges on RaDe targets and KPIs } \\
\hline A & $\bullet$ No specific challenges. \\
\hline B1 & $\begin{array}{l}\bullet \text { No specific RaDe targets are in place. } \\
\bullet \text { The individual process durations are not measured. }\end{array}$ \\
\hline B2 & $\bullet$ The cost metrics are not implemented yet. \\
\hline C & $\bullet$ No specific challenges. \\
\hline D & $\begin{array}{l}\bullet \text { Project cost and progress are not measured. } \\
\bullet \text { No specific RaDe targets are in place. }\end{array}$ \\
\hline
\end{tabular}

Table 7. Specific challenges on product data management

\begin{tabular}{|l|l|}
\hline \multicolumn{1}{|c|}{ Case } & \multicolumn{1}{|c|}{ Company-specific challenges on Product Data Management } \\
\hline A & $\bullet$ PDM system supports inefficiently product modularity analysis and management. \\
\hline B1 & $\bullet$ Lack of proper documentation and knowledge transfer issues. \\
\hline B2 & $\bullet$ No specific challenges. \\
\hline C & $\bullet$ No PDM system available. \\
\hline D & $\bullet$ No specific challenges. \\
\hline
\end{tabular}


Table 8. Specific challenges on DfX

\begin{tabular}{|l|l|}
\hline \multicolumn{1}{|c|}{ Case } & \multicolumn{1}{c|}{ Company-specific challenges on DfX } \\
\hline A & $\begin{array}{l}\text { - The scope of the DfX in RaDe is very narrow and the guidelines are not strictly followed. } \\
\text { - The modification request is often unclear. }\end{array}$ \\
\hline B1 & $\begin{array}{l}\text { - DfX has not been implemented as a concept and is not a known terminology. } \\
\text { - Requirements may be unclear. RaDe organization lacks requirements management knowledge. }\end{array}$ \\
\hline B2 & $\begin{array}{l}\text { - DfX has not been implemented as a concept and is not a known terminology. } \\
\text { - Requirements may be unclear. }\end{array}$ \\
\hline C & $\begin{array}{l}\text { - DfX is recognized as a concept but design rules are only partially documented. } \\
\bullet \text { Customer requirements may be unclear. }\end{array}$ \\
\hline D & \begin{tabular}{l} 
DfX has not been implemented as a concept and is not a known terminology. \\
\hline
\end{tabular} \\
\hline
\end{tabular}

\section{Rapid Development Enablers}

In this part, the enablers or prerequisites for implementing rapid development in companies are proposed. The six enablers deriving from the literature, the case companies' interviews and from the analysis of the challenges regarding RaDe projects can be summarised as follows:

\section{Definition of the concept of rapid development}

The concept of rapid development could be unraveled through fundamental questions such as: what rapid development is, as well as why, when and how to perform RaDe. The positive outcomes of owning and engaging this kind of model for unexpected and time-critical incremental product development should be understood. The scope of RaDe should be identified; RaDe project aims at creating new sales items by quickly modifying an existing product fitting the existing product portfolio. The company should be capable of identifying the different development requirements as well as establish rules and criteria in order to select the right development model - subsequently choosing the RaDe model appropriately. The existing product portfolio should also be structured for rapid development (e.g., high product modularity) and according to the common product data management and portfolio management concept in order to reach the high utilization of common items both in commercial and technical portfolios.

\section{Creation of the RaDe targets and KPIs}

The RaDe targets and KPIs should be defined. Metrics such as project cost or processes duration should be measured. The targets should be connected to the strategic product portfolio management targets to ensure that the products to be developed fit with the company strategy. The lifecycle of every individual item from the company product portfolio must be identified.

\section{Creation of RaDe governance model and team setups}

A permanent, nominated and competent RaDe organization should be established. The related RaDe team shall be dedicated, co-located, autonomous, cross-functional and able to perform small effort projects without bureaucracy. Competent individuals involved in the RaDe type of activities and efficient people management approach is crucial. To ensure a rapid delivery of the product developed through RaDe, a fast and lean governance model must be defined in relation to the product portfolio management. The stakeholders and their requirements should be acknowledged and considered. 


\section{Creation of RaDe processes and tools}

RaDe processes and tools should ensure efficient and fast decision making whether or not initiate the project and then delivering the product in the agreed terms. RaDe may be described in form of a clear but flexible workflow including the business case and decision-making process. The Rapid development organization should rely on the experts, who are actually doing the work from beginning to end of the project and not be based on a too rigid, hierarchical and well-structured process, which may delay the product development. The tools for RaDe should facilitate the accomplishment of all the activities in a coordinated manner in order to achieve the agreed delivery time to the customer.

\section{Data availability and reporting}

The data availability capabilities should be created according to the needed information for initiating and performing RaDe projects. The required information should be clear and connected to company's product data and product portfolio management concepts closely. RaDe concept, targets and KPIs should be understood and recognized by the involved personnel in order to develop the data specification in case of RaDe. The original requirements for RaDe should be well specified and documented at an early stage of the project and at the end, the lessons learned must be considered and preserved for future activities.

\section{DfX}

The DfX concept should be taken into use for the requirement management; the product design changes in case of RaDe should entail minimal or no changes in the receiving business processes, thus allowing the fast and cost-efficient start of product sales, delivery, and care activities by the business processes. For instance, no new supplier should be involved in RaDe projects and the existing suppliers should be qualified so that they are capable of providing the needed modules or components in case of RaDe.

\section{DISCUSSION}

NPD research has been ongoing in the last decades and nearly every company is utilizing a milestonedriven model or similar to develop their new products (Cooper, 2009). This model presents a number of advantages including problem identifications, progress assessment and product quality assurance (Cooper, 1986; Ulrich \& Eppinger, 2000). However, this model may not fit every product development needs and using multiple approaches for managing different types of product development is crucial (Becker, 2006; Cooper, 2008; Ward, 2007). This article focuses on the managerial viewpoint of the lighter and shorter product development process called Rapid development. New insights on the challenges faced by companies to run the rapid product development projects are provided. Enablers to implement $\mathrm{RaDe}$ are also proposed. Results are aligned with the current literature stating that in order to achieve faster product offering, a different structure and management compared to the traditional NPD model is necessary (Birkinshaw \& Gibson, 2004; Tushman \& O'Reilly, 1996). Additionally, $\mathrm{RaDe}$ projects should not cause a need to adapt the supply chain processes to allow immediate product ramp-ups. The scope of changes in case of $\mathrm{RaDe}$ should be restricted so that no new supply chain capabilities should be created (such as no new supplier nor new manufacturing technologies). This is consistent with findings concerning supplier involvement in the case of RaDe (Niskanen et al., 2015). 


\section{Managerial Insights}

The findings can aid business managers in understanding the role of $\mathrm{RaDe}$ as an alternative product development framework, which supplements the traditional NPD. When the current product portfolio fails to satisfy economic and strategic business needs, RaDe model should be used to find a solution within a limited and short timeframe. RaDe is not meant for developing radical innovations, but rather to create new sales items, which complement the existing product portfolio, in a fast manner. The scope of RaDe should be clear so that small product changes do not lead to a radical innovation. It is worth noting that features from existing products may be removed. Other aspects should be taken into use in the way a competitive product should not only address a short development lead-time but also focus on factors such as cost, performance, and quality. The challenges and the enablers for implementing RaDe model can be used by practitioners to understand and initiate this kind concept of product development.

\section{CONCLUSION}

In this study, the practical challenges related to RaDe were identified. Rapid development is seen as a generic challenge regardless the maturity, industry sector or history of the company. Several reasons may inhibit a rapid product development. The ability to create new sales items through $\mathrm{RaDe}$ is a significant challenge in the case companies and only one is capable of doing so. Before RaDe actually takes place, selecting the right product development model and subsequently choosing the rapid development model appropriately is not always seen to be clear even with definite criteria. The decision making whether to start Rapid development project or not is seen challenging and tools for prioritization, evaluation and decision-making are lacking. The developed products through RaDe are not systematically evaluated to determine whether the expected targets have been reached or not. Additionally, getting detailed data for the product development may be challenging due to fragmented databases. Finally, the lack of DfX guidelines and requirements management in case of RaDe may cause complications in the rapid delivery of the products.

The enablers for implementing RaDe must be connected to the main challenges. The initial basic enabler is to enhance the understanding of the idea and concept of RaDe, followed by the creation of the targets and KPIs according to the company strategy. Therefore, RaDe governance model, processes, and tools should be defined and implemented. Furthermore, the utilization of the existing supply chain platforms and the fit of the product to be developed with the current business processes are a prerequisite of RaDe. Finally, the last enabler is the creation of the data requirement specification according to the needed information for initiating and performing RaDe projects.

The limitations of this study include a limited number of case companies and a deeper analysis would increase the validity of the current findings. The study focuses on large and medium-sized companies; hence, the next step would be to study smaller enterprises and other industry sectors. Future research could also focus on studying more in details the implementation of RaDe (such as targets, KPIs, governance model) as well as the impacts of this kind of rapid response model on the receiving business processes (such as Supplier Management or Manufacturing processes). 


\section{REFERENCES}

Abbey, J. D., Guide, V. D. R. Jr, \& Souza, G. C. (2013). Delayed differentiation for multiple lifecycle products. Production and Operations Management, 22(3), 588-602. doi:10.1111/j.1937-5956.2012.01370.x

Barbosa, G. F., \& Carvalho, J. (2013). Analytical model for aircraft design based on Design for Excellence (DFX) concepts and use of composite material oriented to automated processes. International Journal of Advanced Manufacturing Technology, 69(9-12), 2333-2342. doi:10.1007/s00170-013-5211-7

Barczak, G., \& Kahn, K. B. (2012). Identifying new product development best practice. Business Horizons, 55(3), 293-305. doi:10.1016/j.bushor.2012.01.006

Barczak, G., Kahn, K. B., \& Moss, R. (2006). An exploratory investigation of NPD practices in nonprofit organizations. Journal of Product Innovation Management, 23(6), 512-527. doi:10.1111/j.15405885.2006.00221.x

Becker, B. (2006). Rethinking the Stage-Gate process-A reply to the critics. Walthan, MA: Management Roundtable Inc.

Birkinshaw, J., \& Gibson, C. (2004). Building ambidexterity into an organization. MIT Sloan Management Review, 45(4), 47-55.

Brettel, M., Heinemann, F., Engelen, A., \& Neubauer, S. (2011). Cross-functional integration of R\&D, marketing, and manufacturing in radical and incremental product innovations and its effects on project effectiveness and efficiency. Journal of Product Innovation Management, 28(2), 251-269. doi:10.1111/j.1540-5885.2011.00795.x

Brown, S. L., \& Eisenhardt, K. M. (1995). Product development: Past research, present findings, and future directions. Academy of Management Review, 20(2), 343-378.

Browning, T. R., \& Ramasesh, R. V. (2007). A Survey of Activity Network-Based Process Models for Managing Product Development Projects. Production and Operations Management, 16(2), 217-240. doi:10.1111/j.1937-5956.2007.tb00177.x

Cedergren, S., Wall, A., \& Norström, C. (2010). Evaluation of performance in a product development context. Business Horizons, 53(4), 359-369. doi:10.1016/j.bushor.2010.03.001

Cohen, M. A., Eliasberg, J., \& Ho, T. H. (1996). New product development: The performance and time-to-market tradeoff. Management Science, 42(2), 173-186. doi:10.1287/mnsc.42.2.173

Cooper, R. G. (2005). Product Leadership: Pathways to Profitable Innovation (2nd ed.). New York, NY: Perseus Publishing.

Cooper, R. G. (2008). The stage-gate idea-to-launch process-update, what's new and NexGen systems. Journal of Product Innovation Management, 25(3), 213-232. doi:10.1111/j.1540-5885.2008.00296.x

Cooper, R. G. (2009). How companies are reinventing their idea-to-launch methodologies. Research Technology Management, 52(2), 47-57. doi:10.1080/08956308.2009.11657558

Cooper, R. G. (2014). What's Next?: After Stage-Gate. Research Technology Management, 57(1), $20-31$. doi: $10.5437 / 08956308 \times 5606963$

Cooper, R. G., Crawford, C. M., \& Hustad, T. P. (1986). Winning at New Products, by RG Cooper. Journal of Product Innovation Management, 3(4), 307-308. doi:10.1016/0737-6782(86)90024-X

Cooper, R. G., \& Edgett, S. J. (2012). Best practices in the idea-to-launch process and its governance. Research Technology Management, 55(2), 43-54. doi:10.5437/08956308X5502022

Danese, P., \& Filippini, R. (2010). Modularity and the impact on new product development time performance: Investigating the moderating effects of supplier involvement and interfunctional integration. International Journal of Operations \& Production Management, 30(11), 1191-1209. doi:10.1108/01443571011087387

Dombrowski, U., Schmidtchen, K., \& Ebentreich, D. (2013). Balanced Key Performance indicators in product development. International Journal of Materials. Mechanics and Manufacturing, 1(1), 27-31. doi:10.7763/ IJMMM.2013.V1.6 
Eisenhardt, K. M. (1989). Building theories from case study research. Academy of Management Review, 14(4), $532-550$.

Ernst, H. (2002). Success factors of new product development: A review of the empirical literature. International Journal of Management Reviews, 4(1). doi:10.1111/1468-2370.00075

Fisher, M., Ramdas, K., \& Ulrich, K. (1999). Component sharing in the management of product variety: A study of automotive braking systems. Management Science, 45(3), 297-315. doi:10.1287/mnsc.45.3.297

Forza, C., \& Salvador, F. (2008). Application support to product variety management. International Journal of Production Research, 46(3), 817-836. doi:10.1080/00207540600818278

Gatenby, D. A., \& Foo, G. (1990). Design for X (DFX): Key to competitive, profitable products. AT \& T Technical Journal, 69(3), 2-13. doi:10.1002/j.1538-7305.1990.tb00332.x

Gautam, N., \& Singh, N. (2008). Lean product development: Maximizing the customer perceived value through design change (redesign). International Journal of Production Economics, 114(1), 313-332. doi:10.1016/j. ijpe.2006.12.070

Georgiopoulos, P., Fellini, R., Sasena, M., \& Papalambros, P. Y. (2002). Optimal design decisions in product portfolio valuation. In ASME 2002 International Design Engineering Technical Conferences and Computers and Information in Engineering Conference, Montreal, Canada (pp. 593-602). American Society of Mechanical Engineers. doi:10.1115/DETC2002/DAC-34097

Griffin, A. (1997). PDMA research on new product development practices: Updating trends and benchmarking best practices. Journal of Product Innovation Management, 14(6), 429-458. doi:10.1016/S0737-6782(97)00061-1

Hänninen, K., Kinnunen, T., Haapasalo, H., \& Muhos, M. (2013). Sales and R\&D cooperation and integration in the rapid productisation process. International Journal of Business Process Integration and Management, 6(4), 341-351. doi:10.1504/IJBPIM.2013.059139

Hänninen, K., Kinnunen, T., Muhos, M., \& Haapasalo, H. (2014). Decisions in setting up rapid product development projects in SMEs. In $R \& D$ Management conference, Stuttgart, Germany.

Harkonen, J., Haapasalo, H., \& Hanninen, K. (2015). Productisation: A Review and Research Agenda. International Journal of Production Economics, 164, 65-82. doi:10.1016/j.ijpe.2015.02.024

Harkonen, J., Tolonen, A., \& Haapasalo, H. (2017). Service productisation: Systematising and defining offering. Journal of Service Management, 28(5), 936-971. doi:10.1108/JOSM-09-2016-0263

Harmancioglu, N., McNally, R. C., Calantone, R. J., \& Durmusoglu, S. S. (2007). Your new product development (NPD) is only as good as your process: An exploratory analysis of new NPD process design and implementation. $R \&$ D Management, 37(5), 399-424. doi:10.1111/j.1467-9310.2007.00486.x

Holland, S., Gaston, K., \& Gomes, J. (2000). Critical success factors for cross-functional teamwork in new product development. International Journal of Management Reviews, 2(3), 231-259. doi:10.1111/1468-2370.00040

Holt, R., \& Barnes, C. (2010). Towards an integrated approach to "Design for X": An agenda for decision-based DFX research. Research in Engineering Design, 21(2), 123-136. doi:10.1007/s00163-009-0081-6

Hooi Leng, L. (2002). Application of product data management within the product development process (Unpublished doctoral dissertation). University of Huddersfield, England.

Jayachandran, S., Hewett, K., \& Kaufman, P. (2004). Customer response capability in a sense-and-respond era: The role of customer knowledge process. Journal of the Academy of Marketing Science, 32(3), 219-233. doi: $10.1177 / 0092070304263334$

Johnson, M. D., \& Kirchain, R. E. (2011). The importance of product development cycle time and cost in the development of product families. Journal of Engineering Design, 22(2), 87-112. doi:10.1080/09544820902960058

Jugend, D., Araujo, T. R. D., Pimenta, M. L., Gobbo, J. A. Jr, \& Hilletofth, P. (2017). (forthcoming). The role of cross-functional integration in new product development: Differences between incremental and radical innovation projects. Innovation. 
Kaikkonen, H., Haapasalo, H., \& Hänninen, K. (2017). (forthcoming). Characteristics of self-managing teams in rapid product development projects. International Journal of Value Chain Management.

Kaikkonen, H., Hänninen, K., \& Haapasalo, H. (2016). Organizing product development for rapid response. A case study on approaches towards sudden product development needs. In 22nd ICE/IEEE International Technology Management Conference, Trondheim, Norway.

Kärkkäinen, H., Piippo, P., \& Tuominen, M. (2001). Ten tools for customer-driven product development in industrial companies. International Journal of Production Economics, 69(2), 161-176. doi:10.1016/S09255273(00)00030-X

Kinnunen, T., Hanninen, K., Haapasalo, H., \& Kropsu-Vehkapera, H. (2014). Business case analysis in rapid productisation. International Journal of Rapid Manufacturing, 4(1), 14-27. doi:10.1504/IJRAPIDM.2014.062013

Knudsen, M. P. (2007). The relative importance of interfirm relationships and knowledge transfer for new product development success. Journal of Product Innovation Management, 24(2), 117-138. doi:10.1111/j.15405885.2007.00238.x

Krasnikov, A., \& Jayachandran, S. (2008). The relative impact of marketing, research-and-development, and operations capabilities on firm performance. Journal of Marketing, 72(4). doi:10.1509/jmkg.72.4.1

Kuo, T. C., Huang, S. H., \& Zhang, H. C. (2001). Design for manufacture and design for 'X': Concepts, applications, and perspectives. Computers \& Industrial Engineering, 41(3), 241-260. doi:10.1016/S03608352(01)00045-6

Langerak, F., \& Hultink, E. J. (2008). The effect of new product development acceleration approaches on development speed: A case study. Journal of Engineering and Technology Management, 25(3), $157-167$. doi:10.1016/j.jengtecman.2008.06.004

Ledwith, A., Richardson, I., \& Sheahan, A. (2006). Small firm-large firm experiences in managing NPD projects. Journal of Small Business and Enterprise Development, 13(3), 425-440. doi:10.1108/14626000610680280

Lee, H. L., \& Sasser, M. M. (1995). Product universality and design for supply chain management. Production Planning and Control, 6(3), 270-277. doi:10.1080/09537289508930279

Lehto, J., Harkonen, J., Haapasalo, H., Belt, P., Mottonen, M., \& Kuvaja, P. (2011). Benefits of DfX in requirements engineering. Technology and Investment, 2(1), 27-37. doi:10.4236/ti.2011.21004

León, H. C. M., \& Farris, J. A. (2011). Lean product development research: Current state and future directions. Engineering Management Journal, 23(1), 29-51. doi:10.1080/10429247.2011.11431885

Maté, A., Trujillo, J., \& Mylopoulos, J. (2017). Specification and derivation of key performance indicators for business analytics: A semantic approach. Data \& Knowledge Engineering, 108, 30-49. doi:10.1016/j. datak.2016.12.004

Mikkola, J. H., \& Gassmann, O. (2003). Managing modularity of product architectures: Toward an integrated theory. IEEE Transactions on Engineering Management, 50(2), 204-218. doi:10.1109/TEM.2003.810826

Moreno-Moya, M., \& Munuera-Aleman, J. L. (2016). The differential effect of development speed and launching speed on new product performance: An analysis in SMEs. Journal of Small Business Management, 54(2), 750-770. doi:10.1111/jsbm. 12170

Nair, K. R. A., Krishnakumar, S., \& Srinivasan, M. S. (2001). Role of Product Data Management (PDM) in Lean Product Development (technical paper). Presented at SIAT 2001. doi:10.4271/2001-28-0055

Niskanen, T., Hänninen, K., \& Kujala, J. (2015). Supplier involvement in rapid development. International Journal of Management and Enterprise Development, 14(4), 273-287. doi:10.1504/IJMED.2015.073808

Oakes, G., \& von Weissenberg, M. (2015). Governance and Agility in Product Development Organizations. In O. Laasch (Ed.), Responsible Governance - International Perspectives for the New Era (pp. 39-90). New York, NY: Business Expert Press.

Ottosson, S. (2004). Dynamic product development-DPD. Technovation, 24(3), 207-217. doi:10.1016/S01664972(02)00077-9 
Pero, M., Abdelkafi, N., Sianesi, A., \& Blecker, T. (2010). A framework for the alignment of new product development and supply chains. Supply Chain Management, 15(2), 115-128. doi:10.1108/13598541011028723

Philpotts, M. (1996). An introduction to the concepts, benefits and terminology of product data management. Industrial Management \& Data Systems, 96(4), 11-17. doi:10.1108/02635579610117467

Robertson, D., \& Ulrich, K. (1998). Planning for product platforms. Sloan Management Review, 39(4), 19-31.

Sadeghi, A., \& Zandieh, M. (2011). A game theory-based model for product portfolio management in a competitive market. Expert Systems with Applications, 38(7), 7919-7923. doi:10.1016/j.eswa.2010.11.054

Smith, P. G. (1990). Fast-cycle product development. Engineering Management Journal, 2(2), 11-16. doi:10. 1080/10429247.1990.11414568

Smith, P. G., \& Reinertsen, D. G. (1998). Developing products in half the time: new rules, new tools (2nd ed.). New York, NY: John Wiley \& Sons Inc.

Sousa, C. M., Ruzo, E., \& Losada, F. (2010). The key role of managers' values in exporting: Influence on customer responsiveness and export performance. Journal of International Marketing, 18(2). doi:10.1509/jimk.18.2.1

Thomas, D. R. (2006). A general inductive approach for analyzing qualitative evaluation data. The American Journal of Evaluation, 27(2), 237-246. doi:10.1177/1098214005283748

Tolonen, A., Shahmarichatghieh, M., Harkonen, J., \& Haapasalo, H. (2015). Product portfolio managementTargets and key performance indicators for product portfolio renewal over life cycle. International Journal of Production Economics, 170, 468-477. doi:10.1016/j.ijpe.2015.05.034

Tushman, M. L., \& O’Reilly, C. A. III. (1996). The ambidextrous organizations: Managing evolutionary and revolutionary change. California Management Review, 38(4), 8-30. doi:10.2307/41165852

Ulrich, K. T., \& Eppinger, S. D. (2000). Product design and development (5th ed.). New York, NY: McGraw Hill.

Unger, D. W., \& Eppinger, S. D. (2009). Comparing product development processes and managing risk. International Journal of Product Development, 8(4), 382-402. doi:10.1504/IJPD.2009.025253

Van Echtelt, F. E., Wynstra, F., Van Weele, A. J., \& Duysters, G. (2008). Managing supplier involvement in new product development: A multiple-case study. Journal of Product Innovation Management, 25(2), 180-201. doi:10.1111/j.1540-5885.2008.00293.x

Vigna, L., Hänninen, K., Kaikkonen, H., \& Haapasalo, H. (2015). How to build a well-performing team for rapid development. In $R \& D$ Management conference, Pisa, Italy.

Ward, A.C. (2007). Lean product and process development. Cambridge, MA: Lean enterprise institute.

Wheelwright, S. C., \& Clark, K. B. (1992). Revolutionizing Product Development: Quantum Leaps in Speed, Efficiency, and Quality. New York, NY: The Free Press.

Yadav, O. P., \& Singh, N. (2008). Perspectives and challenges for product reliability assurance in the product development process. International Journal of Product Development, 5(1-2), 4-16. doi:10.1504/IJPD.2008.016367

Yang, X., Moore, P. R., Wong, C. B., Pu, J. S., \& Kwong Chong, S. (2007). Product lifecycle information acquisition and management for consumer products. Industrial Management \& Data Systems, 107(7), 936-953. doi:10.1108/02635570710816685

Yin, R. K. (2003). Case study research: Design and methods (3rd ed.). Beverly Hills, CA: Sage Publications Inc. 


\section{APPENDIX}

\section{Background, the Product Development Project Portfolio Of The Case Company}

Product Development Project Portfolio

1. What are the different product development models in the company's product development portfolio? Such as

- Technology development, platform development (Full milestone driven NPD)

- Major new product development (Full milestone driven NPD)

- Medium enhancement type of product development (light NPD, fewer milestones)

- Minor changes (Rapid Development, Rapid Productisation)

2. Are there only global projects or are there regional, country or customer-specific product development projects as well?

3. Are there other types of classifications in your product development portfolio?

4. What is the size of the technology and platform development project portfolios in your company?

- Number of new technology development projects?

- Number of new HW and SW platform development projects?

5. How many product development projects do you carry out annually that result in completely new sales items (NPD projects)?

- Major new product development projects, HW and SW

- Medium new product development projects, HW and SW

- Minor new product development projects, HW and SW

6. How many product development projects do you carry out annually those results in improvements to existing sales items (improvement projects)?

- Major enhancement for existing products (new versions), HW and SW

- Medium enhancements for existing new product development projects, HW and SW

- Minor new product development projects, HW and SW (potential RaDe projects)

7. How are your product development organisation's resources split between different types of projects (platform/technology/NPD/improvement projects) in terms of:

$\circ \quad$ Percentage of projects?

- Workforce/employees?

- Costs?

8. During past years, how has the amount of product development projects developed? (increased/ decreased)

- In platform projects?

- In technology projects?

- NPD projects?

- Improvement projects?

- What have been the root causes of this development?

9. What are your product lifecycle phases?

10. Do you have modular product architecture?

11. Do you have detailed information of your current product architecture/structure/modules available in your current tools?

12. How many stages/gates exist in your NPD process? How are they distributed along the whole process?

Portfolio Management for Product Development Projects 
13. Do you have an organisational unit or a cross-functional steering body for product portfolio management?

14. Do you have any descriptions available for the related governance model?

15. Who is the chair of the cross-functional steering body and the related stakeholders?

16. How many persons are involved in product development project portfolio management activities?

17. How much power do different participants (roles) have in product development portfolio management steering group?

18. What is the frequency of your planned product development project portfolio management meetings?

- What is the standard agenda of these planned product development portfolio management meetings?

19. What are the main tools utilised in product development portfolio management?

- Within projects/product evaluation?

- Prioritisation and decision-making? (Strategic approaches, diagrams, matrices, financial KPIs, simulations, mathematical methods, etc.)

20. How do your tools support collaboration with suppliers for adequate information sharing during development?

21. What kind of communication and change management tasks are done by product development project portfolio management?

$\circ \quad$ Who does this communication?

Criteria for the Selection of Product Development Models

22. How is prioritisation between development projects done during New Product Development?

23. What are the evaluation criteria to prioritise which product development projects are to be started or continued?

- How is business case investigation and planning conducted?

- What are the stages in business case evaluation?

24. What are product development project portfolio management targets/key performance indicators (KPIs)?

25. What are the tools utilised in prioritisation and evaluation? For example:

- Design-for-X (DfX) requirements from receiving business processes point of view

- Size of the technical changes

- Size and number of needed new functionalities

- Size of the planned work amount

- Time-to-market

- Size of the project budget

- Number of participating R\&D locations

- Something else, please describe?

\section{Rapid Development Process and Project Management}

\section{Rapid Development Process}

26. What is the strategic goal of RaDe type of product development?

- Consumer needs for a new product functionality?

- Competition's performance?

- Cost reduction?

- Geographical differentiation?

- Something else, please describe? 
27. What kind of information is needed to decide between different product development models? - How do you decide whether a product development is NPD or RaDe?

28. What kind of impact does the following criterion have in the decision between an NPD and RaDe project?
- Architectural compatibility
- Needed (development) work effort
- Development time
- Needed resources
- Demand for other markets or customers
- Design for variability
- Product strategy
- Product variation

29. What kinds of products are usually carried out using Rapid Development?

30. What kind of product change requirements are usually carried out using Rapid Development?

31. What are the major process changes for the Rapid Development process compared to NPD?

32. What are the typical project phases in Rapid Development type of product development?

- Do you have any process descriptions available?

33. How many stages/gates exist in your Rapid Development process?

- How are these stages different from normal NPD stages?

34. Are there mandatory development phases that must be done in every product development project? (Including NPD and RaDe)

35. Which phases can be compromised or overlooked in order to achieve agility and speed in Rapid Development projects?

36. What is the typical duration of a Rapid Development project? (comparison with full-scale NPD)

37. What is the distribution of time spent in each phase of Rapid Development?

38. What is the distribution of costs spent in each phase of Rapid Development?

39. Are the following development phases used in Rapid Development, or are they rather used in normal NPD type of product development projects?

- Feasibility study (Including requirement management and feature management)

- Project planning

- Specification and conceptualising

- Design

- Development and integration

- Piloting and testing

- Ramp up

40. Who are the stakeholders involved in each phase?

- What is the nature of your customer requirement screening process?

41. What are the decision-making points in Rapid Development projects?

- Are these decision-making points time-based or does the project need to fulfil milestone criteria first?

RaDe Governance Models and Decision Making Bodies

42. Who are the stakeholders influencing and having requirements for the Rapid Development activities?

- What is the role of the different stakeholders in the RaDe value chain?

- What is the impact of the different stakeholders in the RaDe value chain?

- What is the contribution of the different stakeholders in the RaDe value chain?

43. What kind of governance model, steering and management boards are organised for initiating and managing Rapid Development projects? 
44. How does the decision making take place to initiate a Rapid Development project?

45. How are Rapid Development projects established? (such as nomination of the project manager and a team)

46. How is the decision making organised during Rapid Development projects?

- What kinds of decisions can be made internally by the Rapid Development project team and what kinds of decisions need to be raised to higher steering bodies?

RaDe Project Management

47. What is the frequency of the planned Rapid Development project management team meetings?

48. Who are the participants in Rapid Development project management meetings?

- What are the standard agenda topics of these meetings?

49. How are rapid development projects organised in the company? For example:

- By Business Units and Business lines?

- In some other way, such as the type of product development projects?

50. Who has the financial responsibility to make budget allocation decisions (e.g. the size of the overall project budget and its allocation within the project) in Rapid Development teams?

51. Who has the responsibility for project planning and project management in Rapid Development projects?

Product Development Targets and Key Performance Indicators (KPIs) for Rapid Development

52. What are the targets and the metrics for product development projects? Including both NPD and RaDe projects.

- Is there any difference in terms of targets and metrics for RaDe projects?

53. What are the typical targets and KPIs for rapid development type of product development projects?

54. How do you measure the progress of rapid development projects?

55. What is the difference in delivery capability creation of rapid development compared to NPD?

56. What is the difference in sales capability creation of rapid development compared to NPD?

57. What is the difference in service capability creation of rapid development compared to NPD?

Organising Rapid Development

58. Do you have any challenges in product ownership and product governance related issues in Rapid Development?

59. What are the main challenges related to product portfolio management in Rapid Development:

- In product portfolio target setting and measurement related issues?

- In portfolio management process related issues?

- In portfolio management tools related issues?

- In portfolio and product data (and data availability) related issues?

- Something else, please describe?

60. How would you improve your company's product portfolio management related to Rapid Development?

61. What are the success factors for Rapid Development projects?

\section{Team Set Up and Collaboration}

New Product Development (NPD) Project Team Setup 
62. What is the composition of your NPD teams?

63. Who do the NPD team members report to during the projects and how?

64. Who are the team leaders in NPD projects?

65. How are the NPD teams tasks assigned?

66. What is the extent of self-management in NPD teams?

67. How big are the NPD teams and are there any differences based on different types of projects?

68. How are people assigned and/or chosen for NPD teams?

69. What is the level of work spent on the project for the NPD team members? (Full-time vs. Part-time)

70. Are NPD teams co-located or dispersed between different locations?

71. Have you defined a core team and an extended team for NPD projects?

72. What are the core competencies of people in NPD projects?

- Project Management

- HW creation

- SW creation

- Integration and verification

- Sales Capability Creation (Marketing, Sales and Contracting)

- Delivery Capability Creation (Purchasing, manufacturing, testing, logistics)

- Service Capability Creation (product installation, product implementation, use, maintenance and repair)

73. How do you ensure NPD team members know the common commitment and goals?

74. How are NPD teams rewarded?

75. How much can the NPD teams influence their own work practices?

Rapid Development Project Team Setup

76. What is the composition of your Rapid Development teams?

- Are there differences between NPD and Rapid Development projects in regards to team composition?

77. Who do the Rapid Development team members report to during the projects and how?

- What is the number of managerial levels in Rapid Development projects?

78. Who are the team leaders in RaDe projects?

79. How are the Rapid Development teams' tasks assigned?

80. What is the extent of self-management in Rapid Development teams?

81. How big are the Rapid Development teams and are there any differences based on different types of projects?

82. How are people assigned and/or chosen to Rapid Development teams?

83. What is the level of work time spent on the projects for the Rapid Development team members? (Full-time vs. Part-time)

84. Are Rapid Development teams co-located or dispersed between different locations?

85. Have you defined a core team and an extended team for Rapid Development projects?

86. What are the core competencies of people in Rapid Development projects?

- Project Management

- HW creation

- SW creation

- Integration and verification

- Sales Capability Creation (Marketing, Sales and Contracting)

- Delivery Capability Creation (Purchasing, manufacturing, testing, logistics)

- Service Capability Creation (product installation, product implementation, use, maintenance and repair) 
87. How do you ensure Rapid Development team members know the common commitment and goals?

88. How are Rapid Development teams rewarded?

89. How much can the Rapid Development teams influence their own work practices?

Collaboration and Communication in Rapid Development Teams

90. What kind of communication mechanisms are used in your Rapid Development projects?

- Do you feel that your current communication mechanisms are adequate?

- Could you describe a situation, where the communication in your team was working well? Why was it working well?

- Could you describe a situation, where the communication in your team was not working well? Why was communication not working well?

91. How are the communication and collaboration mechanisms defined in Rapid Development teams? (Open vs. well-defined)

92. How is information managed in during Rapid Development projects?

- How is information or data shared if necessary?

93. What are the main challenges in communication?

- How do you overcome these challenges?

94. How do you communicate with customers during Rapid Development projects?

95. How do you communicate with other stakeholders during Rapid Development projects?

96. What kind of information is needed from suppliers during Rapid Development?

- What kind of information is needed by suppliers during Rapid Development?

97. What kinds of tools are used for virtual communication in Rapid Development? (Virtual communication includes instant messaging, email, wikis, intranets, etc.)

- Are your virtual communication tools effective?

98. When do you use face-to-face communication rather than virtual?

99. How the teams cooperate with other development teams during projects? (Formally? Informally?)

Knowledge Creation and Problem-Solving in RaDe Projects

100. How are problems in development projects handled?

101. How are solutions to problems/new ideas shared between team members and other members of your organisation?

102. Do you think that the expertise of all the team members is fully utilised when solving the problems?

- Could you describe a situation, where you were able to efficiently solve a problem in your team? Why was problem-solving working well?

- Could you describe a situation, where your team was not able to solve a problem in your team? What was it not working well?

103. Do you organise training for your development team members?

104. If an employee wishes to learn a new skill, how would he approach the issue?

105. What would you do in a situation, where you notice that your team's expertise is not enough to solve the problem?

\section{DfX, Business Process Requirements and Product Design Rules}

DfX Stakeholders and Requirements

106. Who are your internal stakeholders? What are their requirements? 
107. Who are your external stakeholders? What are their requirements?

108. How are the coordination \& communication requirements from both internal and external partners acknowledged by the company?

109. How are the requirements prioritised?

110. How are the conflicting requirements from various stakeholders addressed?

111. On what basis is each requirement measured? (targets)

112. What are the DfX concepts/disciplines in your company?

113. What is targeted by DfX in the company?

114. What are the particular business benefits in the organisation intended to be achieved through various DFX considerations?

115. What are the typical DfX targets and KPIs?

116. What are the typical related DfX product design guidelines?

117. What procedure or principles are taken into use by the organisation to implement DfX practices?

118. How are the design requirements managed in your organisation?

119. What steps have been taken during early product development to prepare sales/delivery/service capabilities?

120. How is the training relevant to DfX or other procedures conducted?

- Who is responsible for the training sessions and to whom are they conducted?

121. Does the company have any initiatives supporting simultaneous product development activities and development activities for receiving business processes (concurrent engineering)? If yes how is it done?

Management and Tools of DfX

122. How is the DfX management organised?

123. How is the communication of needs of different DfX disciplines coordinated into product development and the order-delivery process?

124. Who are the key responsible persons for each discipline? What are their roles?

125. How is the DfX information managed? What kinds of tools are used for information management?

126. How are the DfX activities organised in product development projects? Is the organisational structure/team setup standard for all the product development process? If not, on what basis does it change?

127. How are the DfX tools categorised (guidelines, checklist, metrics, math model, method)?

- What DfX considerations do these tools include?

128. Could you describe your DfX tools in detail (attach documents if necessary)?

- Are these tools standard for all the projects?

- Are these tools supported by any software program? If yes, how is it supported?

129. What are the DfX challenges identified in the organisation?

130. What steps have been taken for improvement of DfX approach?

DfX in Rapid Development Projects

131. What is the DfX approach for RaDe projects?

132. In what phases of Rapid Development is DfX approach implemented?

133. How is your DfX approach different in your Rapid Development projects compared to NPD?

134. What are the DfX factors added or compromised in a Rapid Development project?

135. What are the DfX factors common for both NPD and Rapid Development projects?

136. Are the DfX tools used for Rapid Development projects different from that of NPD?

- If yes, how is it different? 
137. What are the most important DfX factors from Rapid Development perspective?

138. Did these questions bring up anything else that you would like to share about Rapid Development?

Jordan Verrollot received MSc in 2012 from the University of Technology of Troyes, France. He joined Industrial Engineering and Management, Faculty of Technology at the University of Oulu, Finland in 2014. His research interests include supply chain management, product management, product portfolio management and product development.

Arto Tolonen received an MSc in Engineering (1992) and Dr (Tech) in Industrial Engineering and Management (2016) from the University of Oulu, Finland. Currently, he is a Senior Research Fellow in Industrial Engineering and Management at the University of Oulu. His current research interests are product management, product portfolio management, product data management and rapid product development. He has over 20 years of experience in development of business processes and operational management of Design for Excellence product design principles, delivery capability creation, supply chain management and product data management in global companies.

Janne Harkonen received Bachelor's degree (1st Class Honours) in Engineering Business Management from the University of Greenwich in the UK and both MSc in Process Engineering and Dr (Tech) in Industrial Engineering and Management, from the University of Oulu, Finland. He has also studied in the University of North Carolina at Wilmington, USA. He has experience working in the IT and environmental technology industries. Currently, he is a Senior Research Fellow at the University of Oulu in Finland. Dr Harkonen has authored and co-authored over 50 journal articles, and also a number of other publications.

Harri J. O. Haapasalo is a Professor of Product Management at Industrial Engineering and Management, University of Oulu in Finland. He has two main areas of research: one in product management, product development and the second one in the area of complex systems management, lean construction and business models. He has been very active in obtaining research projects, and active in journal publications. His list of publications contains more than 250 international items. He has supervised more than 30 doctoral theses and been an external examiner for more than 30 doctoral dissertations. 